\title{
Activity in Fetal Bovine Serum That Stimulates Erythroid Colony Formation in Fetal Mouse Livers Is Insulinlike Growth Factor I
}

\author{
Armin Kurtz, Wolfgang Härtl, Wolfgang Jelkmann, Jürgen Zapf, and Christian Bauer \\ Physiologisches Institut der Universität Zürich-Irchel, Universität Zürich, 8057 Zürich, Switzerland; Physiologisches Institut der \\ Universität Regensburg, Universität Regensburg, 8400 Regensburg, Federal Republic of Germany; Physiologisches Institut der \\ Medizinischen Hochschule Lübeck, Medizinische Hochschule Lübeck, 2400 Lübeck, Federal Republic of Germany; and Stoffwechsellabor, \\ Medizinische Klinik, Universitätsspital, 8091 Zürich, Switzerland
}

\begin{abstract}
In the present study, the erythropoietic activity of fetal serum was characterized. Using fetal bovine serum (FBS) as a source of the erythropoietic activity and serum-free cultures of fetal mouse livers (FMLC assay) as a detection system, we found that FBS stimulated colony formation from late erythroid progenitor cells (CFU-E) in a dose-dependent fashion. The slope of the dose-response curve, however, was significantly different from that for erythropoietin (Ep), the best-characterized erythropoietic activity so far. The erythropoietic activity of FBS was found in the 120-160- and 40-70-kD range at neutral $\mathrm{pH}$. In the presence of $1 \mathrm{M}$ acetic acid, however, the erythropoietic activity had an apparent molecular mass between 3 and $13 \mathrm{kD}$. From ion exchange experiments with DEAE-cellulose, the isoionic point of the activity was estimated to about pH 5 . Furthermore, the erythropoietic activity of FBS was found to be co-eluted on Sephadex G-150 with the binding proteins of insulinlike growth factors (IGF). The IGF I concentration determined by radioimmunoassay was $70 \mathrm{ng}$ IGF I/ml. The Ep activity of FBS was $<5 \mathrm{mU} / \mathrm{ml}$ when determined with the posthypoxic polycythemic mouse assay for Ep. These results suggest that the erythropoietic activity of FBS is related to IGF and not to Ep. The erythropoietic activity of FBS was abolished by an antiserum against IGF I. Furthermore, IGF I was a factor of $\sim \mathbf{4 0}$ more potent than IGF II in stimulating erythroid colony formation. All of these findings suggest that the erythropoietic activity of FBS is IGF I.
\end{abstract}

\section{Introduction}

Fetal erythropoiesis is characterized by a strong increase in erythrocyte mass. This increase parallels the whole body growth (1) and is thought to be required for the maintenance of a sufficient energy supply for the growing fetus. The mechanism by which fetal erythropoiesis is tuned to the energy demand of the tissues has not yet been clarified. While the growth of fetal tissues is thought to be under the control of a group of growth factors, including the insulin-like growth factors $(\mathrm{IGF})^{1}(2)$, fetal eryth-

Address correspondence to Dr. Kurtz, Physiologisches Institut der Universität Zürich-Irchel.

Received for publication 10 September 1984 and in revised form 10 June 1985.

1. Abbreviations used in this paper: CFU-E, late erythroid progenitor cells; Ep, erythropoietin; FBS, fetal bovine serum; IGF, insulinlike growth factors.

J. Clin. Invest.

(C) The American Society for Clinical Investigation, Inc.

$0021-9738 / 85 / 10 / 1643 / 06 \$ 1.00$

Volume 76, October 1985, 1643-1648 ropoiesis, like erythropoiesis in the adult organism, is believed to be regulated by the glycoprotein hormone erythropoietin (Ep) (3). The idea that Ep controls fetal erythropoiesis is based mainly on the findings that Ep is present in fetal plasma and that it acts as a mitogen on fetal erythroid progenitor cells in vitro (3). The Ep concentration in fetal plasma, however, is not higher than in the adult plasma (4). This is surprising in view of the fact that fetal, but not adult, erythroid tissue is constantly expanding. Therefore, the question arises whether factors other than Ep are involved in the enlargement of fetal erythroid tissue. A possible candidate is insulin-like growth factor I (IGF I), the mediator of the mitogenic effect of growth hormone (5). Previously (6), we have shown that IGF I, which is present in fetal sera, also stimulates colony formation of fetal late erythroid progenitor cells (CFU-E) (7). On the other hand, fetal bovine serum (FBS) has been shown to stimulate colony formation of CFU-E in vitro (8). In view of these connections, we were interested to get more information about the nature of the erythropoietic activity in FBS. Using FBS as a source of the fetal erythropoietic activity and serum-free cultures of fetal mouse livers as a detection system, we determined the biological and chemical characteristics of the erythropoietic activity.

From a number of biological and biochemical tests, including dose-response studies, gel filtration on Sephadex G-150 and G-50, ion exchange on DEAE-cellulose, and Ep and IGF I determinations, we infer that the erythropoietic activity of FBS is IGF I. Our conclusion was further corroborated by the finding that an antiserum against IGF I abolished the erythropoietic activity of FBS. IGF I, which is identical to somatomedin C (9), is one of the most prominent regulators of growth (5). To our knowledge, this study is the first that provides evidence that the growth of the whole body and the growth of erythroid tissue could be under the control of the same growth factor, namely IGF I.

\section{Methods}

Erythroid colony assay. The erythropoietic activity was assayed by its ability to generate erythroid colonies from CFU-E in serum-free cultures of fetal mouse livers exactly as described in Kurtz et al. (10). Liver cells were obtained from 13-d-old fetal NMRI mice. The total volume of one culture was $600 \mu$ l, including the $60 \mu \mathrm{l}$ of the sample to be assayed for erythropoietic activity. The erythropoietic effect is expressed as the percentage of the maximal number of erythroid colonies that were obtained with a saturating concentration of standard $\mathrm{Ep}(120 \mathrm{mU} / \mathrm{ml})$. The maximal number of colonies was $3,250 \pm 80(x \pm \mathrm{SEM} ; n=21)$ per $10^{5} \mathrm{nu}-$ cleated liver cells.

Erythropoietin assay. Ep activity of fetal bovine serum was determined with the posthypoxic polycythemic mouse assay for Ep exactly as described in Jelkmann and Bauer (11). The sample volume injected was $2 \times 0.5 \mathrm{ml}$ per assay mouse.

Molecular mass determinations were performed on a Sephadex 
G-150 $(2.5 \times 84 \mathrm{~cm})$ and a Sephadex G-50 $(2.5 \times 70 \mathrm{~cm})$ column. The Sephadex G-150 column was calibrated with dextran blue, bovine serum albumin, ovalbumin, chymotrypsinogen, and ribonuclease, and the G-50 column with dextran blue, cytochrome $c$, and aprotinin. All chemicals used for the calibration were obtained from Sigma Chemical Co. (St. Louis, MO). The G-150 column was operated with phosphate-buffered saline (PBS), pH 7.4, at $4^{\circ} \mathrm{C}$, and the G-50 column with PBS or 1 $M$ acetic acid at room temperature. The G- 150 and G-50 column were loaded with 2.5 and $2 \mathrm{ml}$ of FBS, respectively. For determination of the elution profile of the erythropoietic activity from the G-150 column, fractions containing $13 \mathrm{ml}$ were concentrated by ultrafiltration on Amicon YM-10 membranes to $1 \mathrm{ml}$ and subsequently assayed in the cultures. For determination of the erythropoietic activity in the void volume and the 3-13-kD range of the G-50 column, the void volume fraction was concentrated to $1 \mathrm{ml}$ and the 3-13-kD range fraction was lyophilized and resuspended in $1 \mathrm{ml}$ of PBS. When $1 \mathrm{M}$ acetic acid was used for elution, the void volume fraction was dialyzed against PBS before assay.

Binding of the erythropoietic activity to DEAE-cellulose was investigated at $\mathrm{pH}$ 7.0, 6.0, 5.5, 5.0, 4.5, and 4.0. Starting buffers were 20 $\mathrm{mM}$ phosphate buffer (pH 7.0-5.5) and $50 \mathrm{mM}$ acetate buffer (pH 5.04.0). Bound material was eluted with $0.5 \mathrm{M} \mathrm{NaCl}$ and $0.1 \mathrm{M} \mathrm{Na}_{2} \mathrm{HPO}_{4}$ as described in Goldwasser et al. (12). For each experiment, $3 \mathrm{ml}$ of FBS was dialyzed against the starting buffer. Bound and unbound material was always concentrated to $1 \mathrm{ml}$ and dialyzed against PBS before assay.

Identification of IGF-binding proteins in FBS. $2 \times 3 \mathrm{ml}$ FBS preincubated with $10 \mu \mathrm{Ci}{ }^{125} \mathrm{I}$-IGF I for $18 \mathrm{~h}$ at $4^{\circ} \mathrm{C}$ were chromatographed on Sephadex G-150 as described above and the elution of the radioactivity was monitored.

Determination of IGF I concentrations. All samples to be assayed for IGF I contents were gel chromatographed on Sephadex G-50 with 1 M acetic acid as described in Zapf et al. (13). Material appearing in the 313-kD range was lyophilized and assayed with a radioimmunoassay for IGF I (14).

Treatment of FBS with IGF I antiserum. Serum of rabbits immunized against pure human IGF I (13) and serum of normal rabbits as control were reacted with FBS as follows: $100 \mu$ l of diluted or undiluted antiserum and $300 \mu \mathrm{l} \mathrm{FBS}$ were mixed and kept at $4^{\circ} \mathrm{C}$ for $24 \mathrm{~h}$. Then $20 \mathrm{mg}$ of Sepharose-coupled Protein A (Sigma Chemical Co.) was added and allowed to react for $90 \mathrm{~min}$ at room temperature. Thereafter, the suspension was centrifuged at $8,000 \mathrm{~g}$ and the supernatant was subsequently assayed in the FMLC test for erythropoietic activity. The specificity of the antiserum was tested using the immunoblotting method described by Towbin et al. (15).

Proteins of FBS and IGF I standard ( $100 \mathrm{ng}$ IGF I $+0.1 \%$ bovine serum albumin [Sigma Chemical Co.]) were separated by SDS gel electrophoresis (16) on a $10 \%$ polyacrylamide gel. Protein bands were transferred to nitrocellulose filters $(0.2 \mu \mathrm{m}$, BA 83 ; Schleicher \& Schüll, Dassel, Federal Republic of Germany [FRG]) using $60 \mathrm{~V}, 0.8 \mathrm{~A}$ for $1 \mathrm{~h}$. Cellulose filters were dried, incubated in $2 \%$ bovine serum albumin overnight, washed with PBS, and subsequently incubated with rabbit anti-IGF serum $(1: 200)$ or normal rabbit serum $(1: 200)$ for $1 \mathrm{~h}$. Thereafter, filters were washed four times with PBS, treated with peroxidase-labeled goat antirabbit IgG (Nordic, Tillburg, The Netherlands) (1:200) for $30 \mathrm{~min}$, again washed four times with PBS, and reacted with a solution consisting of 4-chloro-1-napthol (Merck, Darmstadt, FRG) $(15 \mathrm{mg} / \mathrm{ml}), \mathrm{H}_{2} \mathrm{O}_{2}(30 \%)$, and PBS (1:0.01:9, vol/vol). Staining was stopped by adding $1 \%$ acetic acid.

Fig. 1 shows the peroxidase staining of the nitrocellulose filters. As indicated by the arrow, a single stained band was observed by blotting IGF I standard against IGF I antiserum (Fig. 1, line $A$ ) as well as by blotting FBS against IGF I antiserum (Fig. 1, line $C$ ). No reaction was observed when IGF I standard or FBS were blotted against normal rabbit serum (Fig. 1, lines $B$ and $D$ ). The molecular mass of the stained band in FBS was identical to that of the IGF I standard.

Human urinary Ep standardized against the International Reference Preparation B was kindly provided by the National Institutes of Health (Bethesda, MD). This Ep was used as standard Ep in the polycythemic mouse assay and in the serum-free cultures of fetal mouse livers.
Figure 1. Peroxidase staining of nitrocellulose filters after immunoblotting of rabbit anti-IGF I serum and normal rabbit serum against IGF I standard and fetal bovine serum. Immunoblotting and staining was done as described in the text. $(A)$ IGF I standard ( $100 \mathrm{ng}$ $+0.1 \% \mathrm{BSA})+$ rabbit antiIGF I. (B) IGF I standard + normal rabbit serum. $(C)$ FBS + rabbit anti IGF I. (D) FBS + normal rabbit serum. Numbers indicate molecular mass regions determined with calibration standards. Arrow indicates a stained band.

Rat Ep was partially purified by heat treatment of plasma from male rats exposed to hypobaric hypoxia (17).

Pure human IGF I and IGF II were a generous gift of Professor R. E. Humbel, University of Zürich, Zürich. Stock solutions of these substances were prepared in Iscoves modified Dulbecco medium (Boehringer, Mannheim, Federal Republic of Germany) supplemented with $0.1 \%$ purified serum albumin (18).

\section{Results}

To determine the Ep concentration in FBS, threefold-concentrated FBS from six different serum batches was assayed for Ep activity in the posthypoxic polycythemic mouse assay for Ep. Threefold-concentrated FBS caused an iron incorporation that was significantly higher than a dose of $0 \mathrm{mU}$ Ep and significantly lower than a dose of $50 \mathrm{mU}$ Ep. Using double-logarithmic plotting of the dose-response curve for human standard Ep, the apparent Ep activity of threefold-concentrated FBS was calculated as $15 \mathrm{mU} / \mathrm{ml}$. The Ep activity of unconcentrated FBS should therefore be $\sim 5 \mathrm{mU} / \mathrm{ml}$.

Fig. 2 shows dose-response curves for FBS and rat and human Ep on erythroid colony formation in serum-free cultures of fetal mouse livers. It is obvious that the slopes of the curves for human and rat Ep are similar, whereas the slope of the curve for FBS is significantly different. The slopes of the curves for Ep are about three times steeper than that for FBS. The effect of FBS on erythroid colony formation corresponds to the effect of a sample containing $\sim 100 \mathrm{mU}$ Ep. The apparent Ep activity of FBS in serum-free cultures of fetal mouse livers is therefore estimated to be $\sim 100 \mathrm{mU}$ Ep/ml FBS.

The molecular mass of the erythropoietic activity in five different batches of FBS was determined by neutral gel filtration using a Sephadex G-150 column. From Fig. 3 it can be seen that the activity had two peaks, one between 120 and $160 \mathrm{kD}$ and another between 40 and $70 \mathrm{kD}$. The activity in the latter range was clearly more potent in stimulating erythroid colony formation than that in the $120-160-\mathrm{kD}$ range. For determination of the Ep content in these molecular mass ranges, $50 \mathrm{ml}$ of FBS was gel filtered and the 160-120- and 70-40-kD fractions were pooled separately and concentrated to $5 \mathrm{ml}$ each. When assayed in the polycythemic mouse assay for Ep, no significant increase in radioiron incorporation could be detected in either sample, which indicates that the Ep concentration in both samples was 


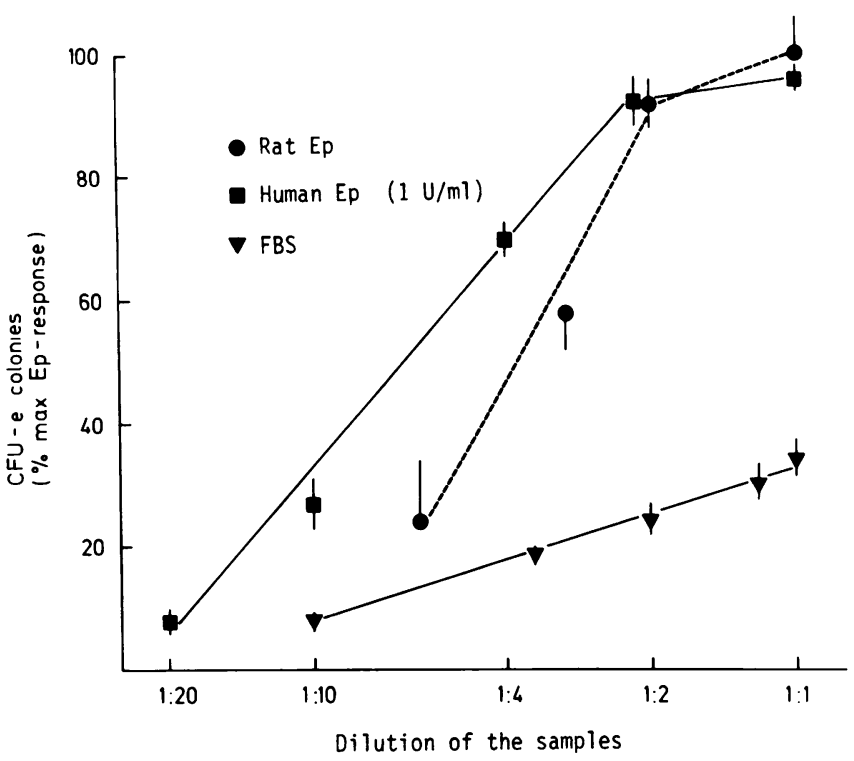

Figure 2. Effect of FBS and human and rat Ep on erythroid colony formation in serum-free cultures of fetal mouse livers at different concentrations. Data are presented as described under Methods. Results are mean \pm SEM of 5,10 , and 3 independent dose-response curves for FBS and human and rat Ep, respectively. The dilution is related to the sample that is added to the cultures and does not include the 10-fold dilution of the samples in the cultures (see Methods).

definitely $<50 \mathrm{mU} / \mathrm{ml}$. Since both samples were 10 -fold-concentrated fractions of FBS, this result indicates that the Ep content in the $120-160$ - and $40-70-\mathrm{kD}$ range of $1 \mathrm{ml}$ of FBS is $<5 \mathrm{mU}$.

The IGF I concentration determined by radioimmunoassay was $70 \mathrm{ng} / \mathrm{ml}$ of FBS. The 160-120- and 70-40-kD ranges contained 2 and $60 \mathrm{ng}$ IGF I/ml FBS, respectively.

To get information about the isoionic point of the activity, the erythropoietic effect of material bound and not bound to DEAE-cellulose at different $\mathrm{pH}$ values was determined. For presentation of the data in Fig. 4, the sum of the effects of bound and unbound material on erythroid colony formation at a certain $\mathrm{pH}$ value was considered as the $100 \%$ value and the effects of bound and unbound material were related to this value. From Fig. 4 it becomes evident that the erythropoietic activity of the

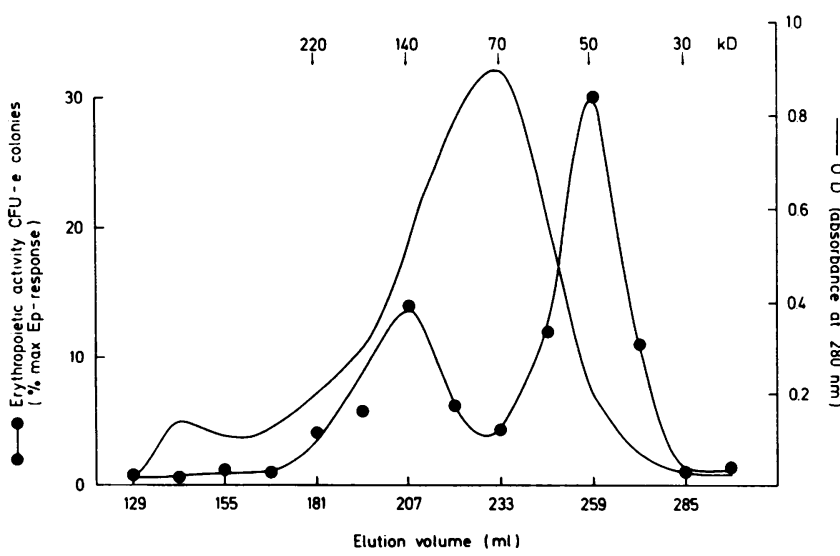

Figure 3. Elution profile from Sephadex G-150 for the erythropoietic activity of FBS at neutral pH. The erythropoietic activity was determined as described in Methods. The curve for the erythropoietic activity represents the mean of five different batches of FBS.

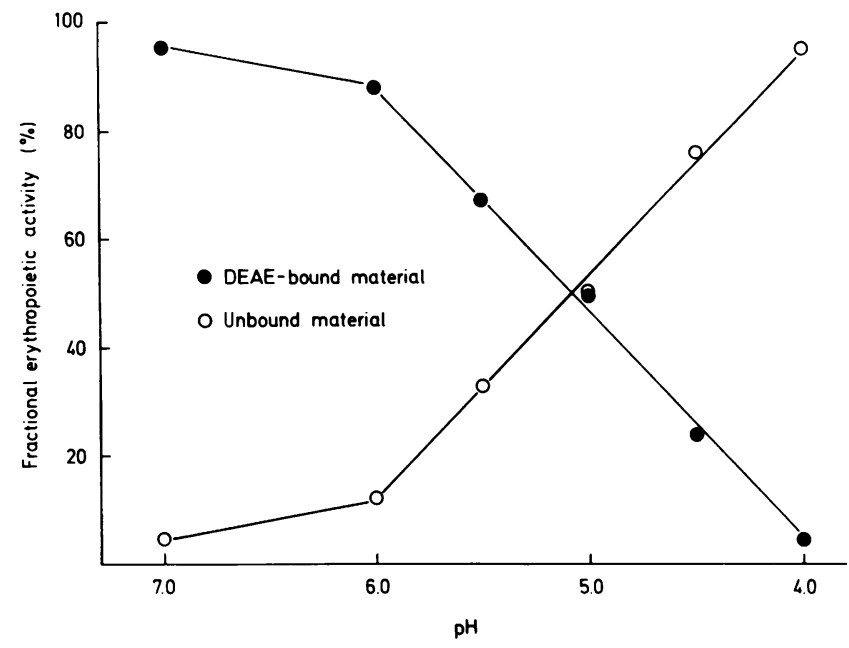

Figure 4. Erythropoietic activity of FBS bound to DEAE-cellulose at different $\mathrm{pH}$ values. As described in Methods, the sum of the erythropoietic effects of bound and unbound material at a certain $\mathrm{pH}$ value was considered as the $100 \%$ value and the activity of bound and unbound material was related to this figure.

unbound material increased with increasing proton concentration. At pH 5.0, the activity of the bound and unbound material was equal, which indicates an isoionic point of $\mathrm{pH}$ 5. The isoionic point of erythropoietin is known to be below pH 4.0 (19), whereas that of purified IGF I is around pH $8.3(20)$. The isoionic point of carrier-bound IGF, however, is not known.

After gel filtration of FBS on a Sephadex G-50 column at neutral $\mathrm{pH}$, all of the erythropoietic activity was eluted in the void volume (Fig. 5, upper panel). This is consistent with the results depicted in Fig. 3. However, when the elution was performed with $1 \mathrm{M}$ acetic acid instead of PBS ( $\mathrm{pH} 7.4$ ), the erythropoietic activity in the void volume largely decreased and activity in the 3-13-kD range appeared (Fig. 5, upper panel). Additional experiments showed that rat and human Ep were always eluted in the void volume in presence of both PBS and $1 \mathrm{M}$ acetic acid (Fig. 5, lower panel).

To obtain information on the molecular mass profile of IGFbinding proteins in FBS, FBS preincubated with $10 \mu \mathrm{Ci}{ }^{125} \mathrm{I}$ IGF I was gel-filtered on Sephadex G-150 at neutral pH. Fig. 6 shows that the main peaks of radioactivity eluted at an apparent molecular mass of 140 and $50 \mathrm{kD}$. For comparison, the elution profile of the erythropoietic activity from Fig. 3 is also included in this figure (broken line). The elution profiles of the radiolabeled IGF I-carrier protein complex and of the erythropoietic activity are more or less identical.

The results obtained from the gel filtration studies suggest that the erythropoietic activity of FBS is related to IGFs. Since both IGF I and IGF II are known to be mitogens, we determined their effects on erythroid colony formation in the serum-free liver cultures. Fig. 7 shows that a 40 -fold-higher concentration of IGF II is needed to obtain the same erythropoietic effect as with IGF I.

Further evidence that IGF I is the erythropoietic activity of FBS was obtained by titration of FBS with antiserum raised against pure human IGF I (see Methods). Fig. 8 shows that the erythropoietic activity of FBS treated with anti-IGF I was clearly dependent on the concentration of antiserum used. The antiserum at a dilution of 1:4 abolished the erythropoietic activity of FBS. 

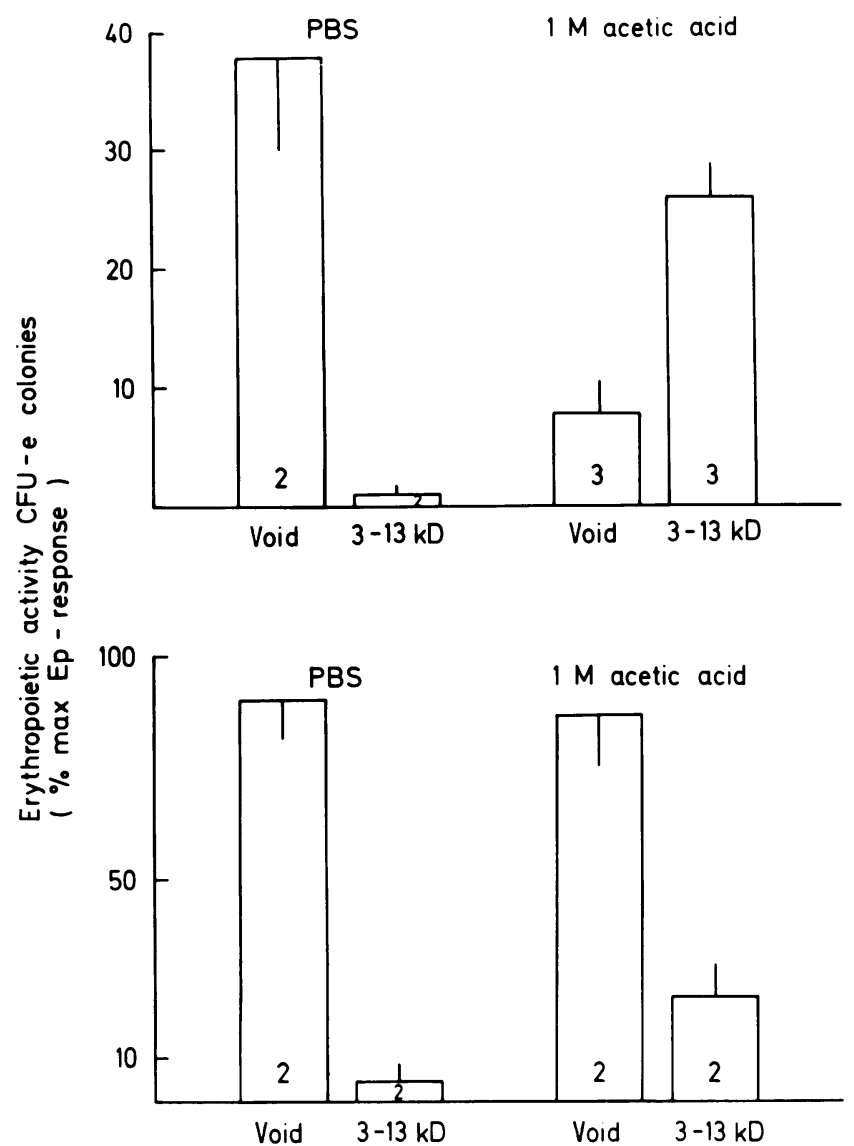

Figure 5. (Upper panel) Erythropoietic activity of FBS in the void volume and 3-13-kD range of a Sephadex G-50 elution in presence of PBS (pH 7.4) and $1 \mathrm{M}$ acetic acid. (Lower panel) Erythropoietic activity of FBS supplemented with $1 \mathrm{U} / \mathrm{ml}$ human Ep (one experiment) and $1 \mathrm{U} / \mathrm{ml}$ rat Ep (one experiment) in the void volume and 3-13-kD range of a Sephadex G-50 elution in presence of PBS and $1 \mathrm{M}$ acetic acid. Data are mean \pm SEM. Figures at the bottom of the columns indicate the number of experiments.

\section{Discussion}

FBS contains significant amounts of erythropoietic activity that stimulates fetal erythroid colony formation from erythroid pro-

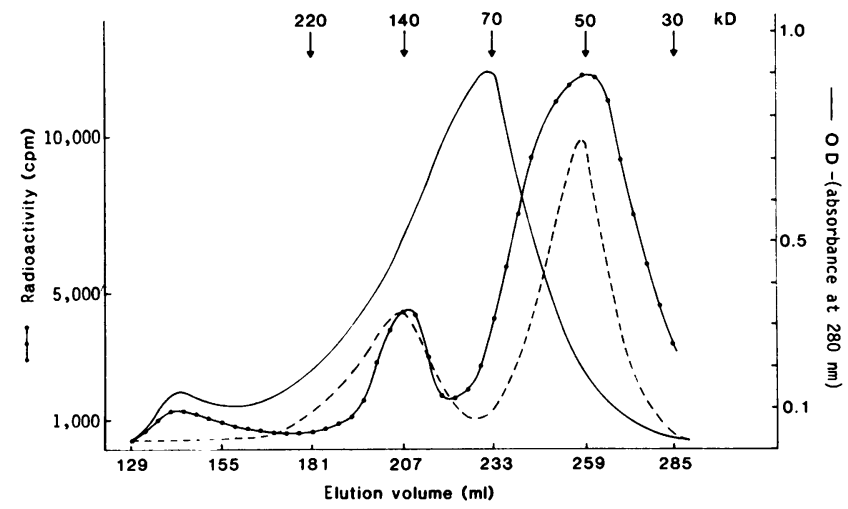

Figure 6. Elution profile from Sephadex G-150 for ${ }^{125} \mathrm{~J}-\mathrm{IGF}$ I, which had been added to FBS at neutral $\mathrm{pH}$. The radioactivity was monitored in elution fractions containing $5 \mathrm{ml}$. The elution profiles of the absorbance at $\mathbf{2 8 0} \mathrm{nm}$ and of the erythropoietic activity (dashed line) as depicted in Fig. 2 are also included in this figure.

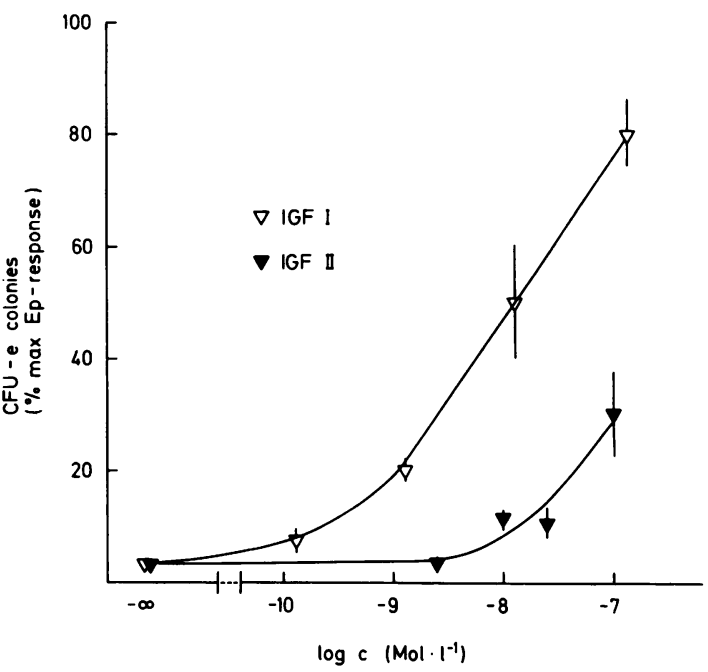

Figure 7. Dose-response curves of IGF I and II for erythroid colony formation in serum-free cultures of fetal mouse livers. Data are given as mean $\pm \mathrm{SEM}$ of three independent dose-response curves for both IGF I and II.

genitor cells (8). The present study was undertaken to identify the biochemical nature of this erythropoietic activity. Since the glycoprotein hormone erythropoietin is so far the best-characterized mitogen for erythroid cells, we shall first discuss whether the erythropoietic activity of FBS is represented by Ep.

When FBS was assayed for Ep activity in a serum-free fetal mouse liver cell assay, the apparent Ep activity of $1 \mathrm{ml}$ of FBS corresponded to $\sim 100 \mathrm{mU}$ of human or rat Ep (Fig. 2). However, when FBS was assayed in the polycythemic mouse test for Ep, the apparent Ep activity of $1 \mathrm{ml}$ of FBS corresponded to $\sim 5$ $\mathrm{mU}$ Ep. This latter finding is in close agreement with the results of Beckman et al. (21) and G. Clemmons (personal communication), who determined the Ep concentration in FBS by radioimmunoassays using anti-human $\mathrm{Ep}(21)$ as well as anti-rat Ep antibodies (Clemmons). Both investigators found between 3 to $9 \mathrm{mU} \mathrm{Ep} / \mathrm{ml}$ of FBS.

Fig. 2 demonstrates that a FBS sample containing $5 \mathrm{mU} / \mathrm{ml}$ of Ep does not yet significantly stimulate colony formation. We therefore conclude that the erythropoietic activity of FBS is due

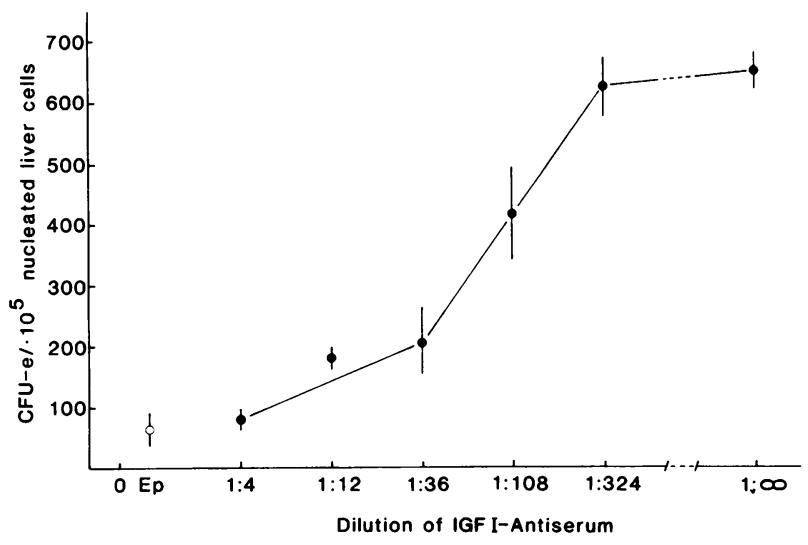

Figure 8. Dependency of erythropoietic activity present in FBS on dilution of added IGF I antiserum. Titration of FBS with IGF I antiserum was done as described in Methods. Results are shown as mean \pm SEM of three experiments. 
to a factor different from Ep. This conclusion is corroborated by the findings $(a)$ that the erythropoietic activity has an isoionic point of $\mathrm{pH} \mathrm{5.0,} \mathrm{which} \mathrm{is} \mathrm{markedly} \mathrm{different} \mathrm{from} \mathrm{that} \mathrm{of} \mathrm{Ep,}$ which is below pH 4.0 (19) (Fig. 4), and (b) that the erythropoietic activity had a significantly reduced molecular mass in presence of $1 \mathrm{M}$ acetic acid, while the molecular mass of rat and human Ep was unchanged under this condition (Fig. 5). Furthermore, the dose-response curve of FBS on erythroid colony formation was significantly different from that for Ep (Fig. 2), a finding that also indicates a difference between Ep and the erythropoietic activity of FBS.

We have shown earlier that human IGF I, a well-known component of a fetal sera, stimulates erythroid colony formation independently of $\mathrm{Ep}$ (7). How likely is it that the erythropoietic activity of FBS is due to bovine IGF I, which has an amino acid sequence identical to that of human IGF I (Honegger and Humbel, personal communication)? IGFs comprise a group of two well-characterized polypeptides named IGF I and IGF II (22, 23) that are potent mitogens of (cf. reference 24). IGF I is identical to somatomedin $C(9)$ and is thought to mediate at least some of the effects of growth hormone (5). IGF I and II have a molecular mass of $\sim 7.5 \mathrm{kD}(22,23)$ and they have been shown to be bound to serum proteins, leaving the concentration of free IGF $<1 \%$ of the total IGF concentration (25). Two types of specific IGF-binding proteins have been described, one occurring in the $150-200-\mathrm{kD}$ range, the other in the $50-\mathrm{kD}$ region $(26$, 27). We determined the molecular masses of the IGF-binding proteins in FBS by adding radiolabeled IGF I to FBS, and we found two peaks, a lower one at $140 \mathrm{kD}$ and a higher one at 50 $\mathrm{kD}$. Interestingly, the elution profile of the radioactivity was identical to that of the erythropoietic activity (Fig. 6). Significant amounts of immunoreactive IGF I were found in the 120-160$\mathrm{kD}(2 \mathrm{ng} / \mathrm{ml})$ and $40-70-\mathrm{kD}(60 \mathrm{ng} / \mathrm{ml})$ ranges. These amounts of IGF I would fully explain the erythropoietic activities found in these two molecular mass ranges by an effect of IGF I (Fig. 7). Furthermore, IGF are known to dissociate from their binding proteins in the presence of $1 \mathrm{M}$ acetic acid (13), and to appear in the low-molcular-weight region under this condition. Exactly the same characteristics were found for the erythropoietic activity of FBS (Fig. 5).

Taken together, all of our results are supportive of the idea that the erythropoietic activity of FBS is due to IGF rather than to Ep. Further support for this was obtained by the experiments shown in Fig. 1 and 8. Treatment of FBS with an antiserum specific against IGF I (Fig. 1) diminished the erythropoietic effect of FBS in a dose-dependent fashion (Fig. 8). This finding strongly indicates that IFG I is the main erythropoietic activity of FBS. This conclusion is further strengthened by the observation that at least human IGF II is 40 times less potent than IGF I in stimulating erythroid colony formation (Fig. 7). Moreover, concentrations of IGFs required for the half maximal effect on growth of CFU-E are very similar to that on growth of fetal fibroblasts, chondrocytes, bone cells (cf. reference 25), and brain cells (28).

Under the assumption that erythropoiesis is humorally regulated in the fetal, as in the adult, organism, the humoral regulator of fetal erythropoiesis should be present in fetal serum. If FBS is accepted to be a source for the humoral regulator of fetal erythropoiesis, then it could be speculated from our findings that fetal erythropoiesis is not mainly governed by Ep but by IGF I. A concept of IGF I-governed fetal erythropoiesis could help us to understand the adaptation of the erythrocyte mass to the whole body mass, since both would then be under the control of the same growth factor. The role of Ep within this concept could be that of a stimulator of erythropoiesis during hypoxic situations of the fetus. This view would be supported by the findings of Jacobson et al. (29), Matoth and Zaizov (1), and Philipps et al. (30), all of which suggest that normal fetal erythropoiesis, which is characterized by a low Ep concentration, is not regulated by an oxygen deficiency. Only in states of severe fetal hypoxia can elevated Ep levels be observed $(3,30)$. Ep then increases exponentially with the degree of hypoxia (30).

The results presented here provide evidence for a role of IGF I in fetal erythropoiesis. The physiological impact of our findings will certainly have to be studied in greater detail.

\section{Acknowledgments}

We are indebted to Prof. Humbel for the generous gift of IGF I and IGF II. We thank Dr. Clemmons for the permission to use her unpublished data about immunoreactive Ep in FBS. We furthermore acknowledge the help of Prof. Humbel and Dr. Zumstein in the determination of IGF I by RIA. Moreover, we are indebted to Prof. Binz for his help in the immunoblotting of anti-IGF I serum. We thank Prof. Moll for helpful discussions.

This work was financially supported by the Sonderforschungsbereich 43 of the Deutsche Forschungsgemeinschaft.

\section{References}

1. Matoth, Y., and R. Zaizov. 1971. Regulation of erythropoiesis in the fetal rat. Israel J. Med. Sci. 7:839-845.

2. Perdue, J. F. 1983. The role of somatomedin/insulin-like growth factors and their receptors on skeletal growth and fetal development: a minireview. In Biology of Cancer: 13th International Cancer Congress. Part B. Alan Riss Inc., New York. 1:405-413.

3. Zanjani, E. D., J. Poster, L. I. Mann, and L. R. Wassermann. 1977. Regulation of erythropoiesis in the fetus. In Kidney Hormones. II. J. W. Fisher, editor. Academic Press, Inc., New York. 463-493.

4. Widness, J. A., J. B. Susa, J. F. Garcia, D. B. Singer, P. Sehgal, W. Oh, R. Schwartz, and H. C. Schwartz. 1981. Increased erythropoiesis and increased erythropoietin in infants born to diabetic mothers and in hyperinsulinemic Rhesus fetuses. J. Clin. Invest. 67:637-642.

5. Schoenle, E., J. Zapf, R. E. Humbel, and E. R. Froesch. 1982. Insulin-like growth factor I stimulates growth in hypophysectomized rats. Nature (Lond.). 296:252-253.

6. Daughady, W. H., K. A. Parker, S. Borowsky, B. Trivedi, and M. Kapadia. 1982. Measurement of somatomedin-related peptides in fetal, neonatal and maternal rat serum by insulin-like growth factor (IGF I) radioimmunoassay, IGF II radioreceptor assay (PRA), and multiplication stimulating activity PRA after acid-ethanol extraction. Endocrinology. 110:575-581.

7. Kurtz, A., W. Jelkmann, and C. Bauer. 1982. A new candidate for the regulation of erythropoiesis-insulin-like growth factor I. FEBS (Fed. Eur. Biochem. Soc.) Lett. 149:105-108.

8. Kanamura, A., T. Okamoto, H. Hara, and K. Nagai. 1982. Developmental changes in erythropoietin responsiveness of late erythroid precursors in mouse hemopoietic organs. Dev. Biol. 92:221-226.

9. Svoboda, M. E., J. J. van Wyk, D. C. Klapper, R. E. Fellows, F. E. Grissom, and R. J. Schlueter. 1980. Purification of somatomedin $\mathrm{C}$ from human plasma: chemical and biological properties, partial sequence analysis, and relationship to other somatomedins. Biochemistry. 19:790-797.

10. Kurtz, A., W. Jelkmann, and C. Bauer. 1983. Insulin stimulates erythroid colony formation independently of erythropoietin. Br. J. Haematol. 53:311-316.

11. Jelkmann, W., and C. Bauer. 1981. Demonstration of high levels of erythropoietin in rat kidneys following hypoxic hypoxia. Pflügers Arch. Eur. J. Physiol. 392:34-39. 
12. Goldwasser, E., W. F. White, and K. B. Taylor. 1962. Further purification of sheep plasma erythropoietin. Biochim. Biophys. Acta. 64: 487-496.

13. Zapf, J., H. Walter, and E. R. Froesch. 1981. Radioimmunological determination of insulin-like growth factors I and II in normal subjects and in patients with growth disorders and extrapancreatic tumor hypoglycemia. J. Clin. Invest. 68:1321-1330.

14. Läubli, U. K., W. Baier, H. Binz, M. R. Celio, and R. E. Humbel. 1982. Monoclonal antibodies directed to human insulin-like growth factor I (IGF I): use for radioimmunoassay and immunopurification of IGF. FEBS (Fed. Eur. Biochem. Soc.) Lett. 149:109-112.

15. Towbin, H., T. Staehelin, and J. Gordon. 1979. Electrophoretic transfer of proteins from polyacrylamide gels to nitrocellulose sheets: procedure and some applications. Proc. Natl. Acad. Sci. USA. 76:43504354.

16. Laemmli, U. K. 1970. Cleavage of structural proteins during the assembly of the head of bacteriophage T4. Nature (Lond.). 227:680-685.

17. Erslev, A. J., J. Caro, E. Cansu, and R. Silver. 1980. Renal and extrarenal erythropoietin production in anaemic rats. Br. J. Haematol. 45:65-72.

18. Iscove, N. N., L. J. Guilbert, and C. Weyman. 1980. Complete replacement of serum in primary cultures of erythropoietin-dependent red cell precursors (CFU-E) by albumin, transferrin, iron, unsaturated fatty acid, lecithin and cholesterol. Exp. Cell Res. 126:121-126.

19. Espada, J. 1977. Chemistry and purification of erythropoietin. In Kidney Hormones II. J. W. Fisher, editor. Academic Press, Inc., New York. 37-71.

20. Humbel, R. E. 1984. Insulin-like growth factors, somatomedins and multiplication stimulating activity: chemistry. In Hormonal Proteins and Peptides. Academic Press, Inc., New York. 12:57-59.
21. Beckman, B., R. D. Belegu, M. Belegu, Y. Katsuoka, and J. W. Fisher. 1982. Hypoxic enhancement of murine erythroid colony formation. In Experimental Hematology Today. Baum, Ledney, and Thierfelder, editors. S. Karger, New York. 53-59.

:22. Rinderknecht, E., and R. E. Humbel. 1978. The amino acid sequence of human insulin-like growth factor I and its structural homology with proinsulin. J. Biol. Chem. 253:2769-2776.

23. Rinderknecht, E., and R. E. Humbel. 1982. Primary structure of human insulin-like growth factor II. FEBS (Fed. Eur. Biochem. Soc.) Lett. 89:283-286.

24. Froesch, E. R., C. Schmid, J. Schwander, and J. Zapf. 1985. Actions of insulin-like growth factors. Annu. Rev. Physiol. 47:443-467.

25. Zapf, J., B. Morell, H. Walter, Z. Laron, and E. R. Froesch. 1980. Serum levels of insulin-like growth factor (IGF) and its carrier protein in various metabolic disorders. Acta Endocrinol. 95:505-517.

26. Daughaday, W. H., A. P. Ward, A. C. Goldberg, B. Trivedi, and M. Kapadia. 1982. Characterization of somatomedin binding in human serum by ultracentrifugation and gel filtration. J. Clin. Endocrinol. Metab. 55:916-921.

27. Zapf, J., E. R. Froesch, and R. E. Humbel. 1981. The insulinlike growth factors (KF) of human serum: chemical and biological characterization and aspects of their possible physiological role. Curr. Top. Cell. Regul. 19:257-309.

28. Lenoir, D., and P. Honegger. 1983. Insulin-like growth factor I stimulates DNA synthesis in fetal rat brain cell cultures. Dev. Brain Res. 7:205-213.

29. Jacobson, L. O., E. Goldwasser, C. W. Gurney, W. Fried, and L. Plzak. 1959. Studies of erythropoietin: the hormone regulating red cell production. Ann. N.Y. Acad. Sci. 77:551-573.

30. Philipps, A. F., J. A. Widness, J. F. Garcia, J. R. Raye, and K. Schwartz. 1982. Erythropoietin elevation in the chronically hyperglycemic fetal lamb. Proc. Soc. Exp. Biol. Med. 170:42-47. 